from a disturbance of electrolyte circulation-that is, the balance of normal body reserves regulated by the processes of secretion and absorption-especially potassium and chloride. But it is difficult to see how such a mechanism would initiate dilatation soon after minor procedures such as the application of a plaster cast, though it may be responsible for maintaining the established case.

A similar acute clinical state has been observed in some patients who were found to have dilatation of the duodenum as far as the point where the superior mesenteric vessels cross the third part. This was recognized many years ago, and moving the patient into the prone position or on to the right side was shown to relieve symptoms in some patients. ${ }^{7}$ On the other hand, the gastric dilatation may have come first and the distension spread to the duodenum, so that compression by the superior mesenteric vessels is really a secondary and perhaps a not very significant phenomenon.

Clinically the onset of acute gastric dilatation may be insidious, with a period of apathy and listlessness before persistent vomiting begins. The vomiting is often bile-stained at first and later becomes brown or black. Physical examination discloses fullness in the left hypochondrium, often with hyperresonance. A plain radiograph of the abdomen shows the dilated viscus, and an erect film may show two fluid levels, one at the fundus and the second below it and to the right due to air trapped in the prepyloric region of the stomach. If any doubt exists the dilated viscus can be demonstrated easily by oral contrast medium.

Treatment is urgent, as circulatory collapse and aspiration of vomit may cause rapid deterioration and death. The stomach should be emptied with a wide-bore tube, and volumes of up to 8 litres have been removed from one patient. ${ }^{6}$ The electrolyte content of the aspirate should be measured as a guide to replacement therapy. Intravenous normal saline (together with potassium if appropriate) should be given to resuscitate the patient.

After the stomach is empty the large tube is replaced by a smaller nasogastric tube and the stomach aspirated until tone returns. Laying the patient prone or on the right side may assist the return of function. Any predisposing factor, such as a plaster cast, should be removed. Operation has little or no place in the management except for the occasional patient in whom a tube cannot be passed, when gastrostomy might be considered.

Most reported series still record a mortality ranging between 25 and $40 \%,{ }^{2} 5$ so that the importance of early diagnosis and energetic treatment cannot be overemphasized.

\section{Fetal Maturity}

Dissatisfaction with the results of assessing gestational age has led to a re-examination of traditional methods. ${ }^{1}$ As a result a bewildering array of new investigations has been introduced.

Clinical assessment of fetal weight is notoriously unreliable, ${ }^{2}$ and even measurement of the size of the uterus is subject to errors in early pregnancy. ${ }^{3} \mathrm{~T}$. Lind ${ }^{4}$ states that the single most valuable piece of information that a clinician can have is an accurate date of onset of the last menstrual period from a woman with a normal regular cycle, but the increasing use of oral contraceptive agents produces a common source of error.

Recently J. G. B. Russell has reported that radiological assessment of gestational age by Blair Hartley's methods is more accurate than menstrual data, ${ }^{5}$ and furthermore that bone maturation is related only to fetal age apart from some acceleration with anencephaly and maternal diabetes and delay with twins and spina bifida. ${ }^{6} \mathrm{~K}$. E. Scott and R. Usher, ${ }^{7}$ however, found that the absence of an upper tibial epiphysis does not distinguish between the underweight full-term baby and the gestationally premature infant. Studies on twins ${ }^{89}$ have conclusively shown the inherent errors in using biological criteria such as the ossification centres, which are subject to numerous influences both known and unknown for the assessment of fetal age.

Ultrasonic measurement of the biparietal diameter of the fetal skull between the twentieth and thirtieth weeks of pregnancy can predict the date of spontaneous delivery to within nine days in $95 \%$ of cases. ${ }^{10}$ Unfortunately, complex and expensive equipment as well as considerable experience is required for this. The method is unreliable after the thirtieth week, and furthermore one-third of babies classed as light for dates post partum had normal growth rates as assessed ultrasonically. ${ }^{11}$

Since the discovery that amniocentesis is a relatively safe procedure in experienced hands ${ }^{12} 13$ various characteristics of the amniotic fluid have been related to menstrual age. Amniocentesis is most difficult when the volume of liquor is low. ${ }^{14} \mathrm{I}$. Brosens and $\mathrm{H}$. Gordon ${ }^{15}$ related the proportion of anucleate squames staining orange with nile blue sulphate to sebaceous activity and hence to menstrual age. Fourteen out of 15 patients between 38 and 39 weeks had over $10 \%$ such cells and 11 patients at or beyond 40 weeks had over $50 \%$ of these cells. It was subsequently realized that absence of orange-staining cells does not exclude a post-term pregnancy. ${ }^{16} 17$ Staining amniotic fluid cells with haematoxylin and

1 Bentrem, G. C., Perkins, P., and Waxman, B., American fournal of Obstetrics and Gynecology, 1970, 106, 917.

Loeffler, F. E., Fournal of Obstetrics and Gynaecology of the British Commonwealth, 1967, 74, 675.

3 Smibert, J., Australian and New Zealand Fournal of Obstetrics and Gynaecology, 1962, 2, 125.

4 Lind, T., British fournal of Hospital Medicine, 1970, 3, 501.

5 Lind, T., British Fournal of Hospital Medicine, 1970, 3, 501. Commonwealth, 1969, 76, 208.

- Russell, J. G. B., and Rangecroft, R. G., Fournal of Obstetrics and Gynaecology of the British Commonwealth, 1969, 76, 497.

Scott, K. E., and Usher, R., New England fournal of Medicine, 1964, 270, 822 .

8 Dee, P. M., Parkin, J. M., and Simpson, W., Clinical Radiology, 1966, 17, 126.

Cope, I., and Murdoch, J. D., fournal of Obstetrics and Gynaecology of the British Empire, 1958, 65, 56.

10 Campbell, S., Fournal of Obstetrics and Gynaecology of the British Commonwealth, 1969, 76, 603 .

11 Willocks, J., Donald, I., Campbell, S., and Dunsmore, I. R., Fournal of Obstetrics and Gynaecology of the British Commonwealth, 1967, 74, 639. 12 Walker, W., British Medical fournal, 1970, 2, 220.

3 Freda, V. J., American fournal of Obstetrics and Gynecology, 1965, 92, 341 .

14 Beischer, N. A., Brown, J. B., and Townsend, L., American fournal of Obstetrics and Gynecology, 1969, 103, 496.

Brosens, I., and Gordon, H., Fournal of Obstetrics and Gynaecology of the British Commonwealth, 1966, 73, 88.

6 Anderson, A. B. M., and Griffiths, A. D., Fournal of Obstetrics and Gynaecology of the British Commonwealth, 1968, 75, 300.

Gynaecology of the British Commonwealth, 1968, 75, 300 .
Chan, W. H., Willis, J., and Woods, J., fournal of Obstetrics and Gynaecology of the British Commonwealth, 1969, 76, 193.

18 Lind, T., Parkin, F. M., and Cheyne, G. A., Fournal of Obstetrics and Gynaecology of the British Commonwealth, 1969, 76, 673.

19 Mandelbaum, B., and Evans, T. N., American fournal of Obstetrics and Gynecology, 1969, 104, 365 .

20 Droegemueller, W., Jackson, C., Makowski, E. L., and Battaglia, F. C., American fournal of Obstetrics and Gynecology, 1969, 104, 424.

1 Huntingford, P. J., and Marsden, D., Geburtshilfe und Frauenheilkunde, 1966, 26, 867 .

22 Pitkin, R. M., International fournal of Gynaecology and Obstetrics, 1969, 7, 199.

23 Mandelbaum, B., La Croix, G. C., and Robinson, A. R., Obstetrics and Gynecology, 1967, 29, 471.

24 Pundel, J. P., Acta Cytologica, 1959, 3, 241.

25 Frampton, J., and Clayton, S. G., fournal of Obstetrics and Gynaecology of the British Commonwealth, 1968, 75, 42.

6 Henry, G. R., Fournal of Obstetrics and Gynaecology of the British Commonwealth, 1969, 76, 795.

27 Beischer, N. A., Brown, J. B., Smith, M. A., and Townsend, L., American fournal of Obstetrics and Gynecology, 1969, 103, 483. 
eosin is less widely used but ensures better cellular detail and enables counts similar to those of vaginal cytology to be made. ${ }^{18}$ Before 32 weeks basal cells predominate, whereas sheets of anucleate squames are characteristic of term.

Of the physiochemical characteristics of the amniotic fluid the most reliable appear to be the concentrations of creatinine and urea. They rise steadily after 30 weeks and reflect increasing fetal renal function, ${ }^{19}{ }^{20}$ as does osmolarity, ${ }^{21}$ which falls during this period. Thus, if the creatinine concentration is greater than $1.6 \mathrm{mg}$. per $100 \mathrm{ml}$. the pregnancy is almost certainly more advanced than 38 weeks and the fetal weight more than 2,500 g. ${ }^{22}$ The converse is not true, and a post-term pregnancy is not associated with a continued rise. The absence of the peak of optical density at $450 \mu$ reflects increasing ability of the fetal liver to conjugate bilirubin and indicates a pregnancy in excess of 36 weeks. ${ }^{23}$ Other less widely used methods are vaginal cytology ${ }^{24}$ and cell counts in amniotic fluid. ${ }^{16}$

It is apparent that all special investigations of menstrual age are subject to error in the very cases where the information is most necessary-intrauterine malnutrition and postmaturity. They can therefore be regarded only as confirmatory to clinical impression when a positive result is obtained. It is still debatable whether routine induction of labour reduces the overall risk to the fetus in a post-term gestation. ${ }^{25} 26$ Functional maturity and fetal well-being are more important than chronological age. ${ }^{25} 27$

\section{Deaf Children}

Education of the deaf child has been a controversial problem since the divergent solutions developed by the Abbé de l'Epée in France and Pastor Samuel Heinicke in Germany during the eighteenth century. They were the forerunners of what are now termed the manual and oral methods, both relying on earlier work.

Manual methods encourage the use of hand gestures to convey meaning by using different positions of the hands and fingers to represent either objects and activities, as in making signs, or the individual letters of the alphabet, as in fingerspelling. Sir Richard Paget ${ }^{1}$ recognized the haphazard and ungrammatical nature of making signs ("signing") and developed a systematic sign language which forestalls much of the criticism previously levelled at such methods. Oral methods rely on perception of the spoken word and the conveying of language by speech. I. R. and A. W. G. Ewing ${ }^{2}$ at Manchester have been the leaders of this approach in Britain. In its most rigorous form teachers have forbidden the use of any form of gesture and lip-reading. On the medical side E. Whetnall ${ }^{3}$ rightly stressed the need for early diagnosis.

Present practice in Britain has been towards the early detection of hearing loss, the fitting of a hearing aid, and pre-

\footnotetext{
' Paget, R., Gorman, P., and Paget, G., A Systematic Sign Language, 4th

${ }^{2}$ Edn. London, the authors, 1969. Manchester University Press, 1954.

3 Whetnall, E., Fournal of Laryngology and Otology, 1956, 70, 630.

3 Whetnall, E., Fournal of Laryngology and Otology,
4 Hine, W. D., Teacher of the Deaf, 1970, 68, 129.

4 Hine, W. D., Teacher of the Deaf, 1970, 68, 129.
s Department of Education and Science, The Education of Deaf Children Department of Education and Science, The Education of Deaf Children;
The Possible Place of Finger-Spelling and Signing. London, H.M.S.O.,

" Conrad, R., Profound Deafness as a Psycholinguistic Problem. Paper presented at Symposium on Speech Communication Ability and Profound Deafness. August 12-14, 1970. Stockholm.
}

school auditory training. It is based on the premise that virtually no child is so profoundly deaf that he has no usable residual hearing. There are some remarkable success stories, and children with $80-90 \mathrm{~dB}$ hearing losses have succeeded in ordinary school, but they are the exception. Even children with less severe deafness, the partially hearing, fall well behind the accomplishments of their normally hearing brothers and sisters. Studies such as W. D. Hine's ${ }^{4}$ indicate a four-year deficit in reading skill by the age of 16 and up to three years in mathematics.

Growing concern with the results of educational practice in this country, particularly in comparison with those reported from Russia and the U.S.A., prompted the Department of Education to set up a committee of inquiry under Professor M. M. Lewis. Its report ${ }^{5}$ considered the value of making signs and of finger-spelling and is essentially an attempt to adjudicate between the two main schools. It performed a valuable service in bringing to a wider public the work of other countries, such as the introduction of finger spelling to preschool children in Russia and the combined hand-mouth system used in Denmark. In the U.S.A. the situation is rather different in that there are two separate traditions, one based on purely oral methods, the other on a combined oral and manual approach, though even here the oral method alone is commonly used in preschool and early school years.

The long-standing polarization between oral and manual methods has clouded the issue for too long. There is undue emphasis on output and on the vocabulary size of the child with a hearing loss and too little consideration of the importance of understanding. Even less consideration has been given to the role of language in the organization of thought, and a deaf child's cognitive abilities are rarely developed to their full potential. Teaching methods, oral or manual, have been derived from an adult understanding of the severe language deprivation of the child. There has been no thought for the qualitative difference between hearing and nothearing. Man acquired spoken language through many generations by a process of learning that necessitated a progressive fusion between what was heard and what was uttered. How far is this process appropriate for a child with little hearing and gross limitation of speech? R. Conrad's ${ }^{6}$ work on memory and recall suggests that the deaf frequently use a different mental imagery from the auditory-articulatory process used by normally hearing speakers. This poses the question, If we try to make the deaf speak like the hearing, are we trying to make them think like the hearing? And we must bear in mind that thought processes mediated by the spoken word are not available to them.

There has been some change in the management of individual children since Amman wrote Surdus Loquens in 1692. But the problems continue to overshadow the solutions so far proposed. Greater skill in medical assessment is needed. The full extent of the perceptual disorder rather than simply the level of threshold hearing levels needs to be studied, as does any impairment there may be of visual and other sensation, and any effect on motor function, particularly in the speech apparatus, as well as on other aspects of the central nervous system. The increasingly powerful resources of experimental and educational psychology should be combined with medicine and developmental linguistics to guide the teacher into new forms of management. 